Mr Dalibor Petrović, poručnik, dipl. inž.

VP 3065 Sombor
SAVREMENI TIP ANALIZE PROBLEMA KONTAKTA SA TRENJEM PRIMENOM KONAČNIH ELEMENATA

UDC: 531.4

Rezime:

Ovaj rad obraduje teorijske metode koje daju rešenje za nelinearne probleme kontakta sa trenjem, a koja proizilaze iz fenomena prianjanja - klizanja. Cilj istraživanja jeste predvidanje napona $i$ deformacija na kontaktnoj površini, kao $i$ unutar komponenti koje dolaze $u$ kontakt, pošto se površina kontakta menja progresivno usled uvođenja spoljnjeg opterećenja. $U$ radu se polazi od pretpostavke da su materijali linearno elastični dok su pomeranja i deformacije male, a površina kontakta kontinualna i ravna. Pretpostavlja se, takođe, da ne dolazi do međusobnog probijanja površina tela u kontaktu. Rad se zasniva na metodi konačnih elemenata prilagođenoj problemima kontakta, na inkrementalno-iterativnoj metodi i na savremenim matematičkim teorijskim postavkama za rešavanje ovog problema.

Ključne reči: kontakt, trenje, čvorni par, kompatibilnost, prianjanje, klizanje, inkrement, iteracija, konvergencija.

\title{
CONTEMPORARY TYPE OF ANALYSIS ON CONTACT PROBLEMS WITH FRICTION USING THE FINITE ELEMENT APPROACH
}

Summary:

This paper elaborates theoretic methods which give solutions for nonlinear problems of contact with friction that arise from stick-slip phenomenon. The aim of the stady is anticipation of tension and deformations on the contact surface as well as inside of components that come in contact, because contact surface is changing progressively owing to outer load induction. In this paper it is presumed that materials are linearly elastic, while motions and deformations are minor, and contact surface is continuous and plane. It is also presumed that it does not come to mutual perforation of the objects surfaces in contact. The paper is based on finite elements method, modified for conctact problems, on iterative-incremental method and with contemporary mathematical theoretical assumption for contact problem solving.

Key words: contact, friction, node pair, compatibility, stick, slip, increment, iteration, convergence.

\section{Uvod}

Noseća struktura letelice, poput većine ostalih tehničkih struktura i sistema, obiluje različitim tipovima mehaničkih spojeva dva ili više tela. Radi tačnog predviđanja snage pogonskog agregata $\mathrm{i}$ ostalih mehaničkih i električnih karakte- ristika neophodno je poznavati stanje kontakta.

U zonama kontakta, koje postoje $\mathrm{u}$ različitim mehanizmima, sile kontakta, zahvaljujući kvazi-statičkim opterećenjima, mogu da dovedu do trenja i do visokih napona, uz pojavu zamora i erozije površina. Zbog toga je potrebno, radi 
projektovanja ovih elemenata, da se predvide sile kontakta i naponi.

Ovaj rad obrađuje razvoj teorijske metode koja daje rešenje za nelinearne probleme kontakta sa nepovratnošću koja proizilazi iz fenomena prianjanje - klizanje. Analiza napona i deformacija, unapređena kroz kontakt dva ili više elastičnih tela, dugo je bila važna tema, ali je teško dobiti numeričke rezultate praktičnih problema uz odgovarajuću tačnost.

Postojanje tačnih rešenja napona kontakta proizvod su visokosofisticiranih matematičkih analiza za idealizovano modelovane konfiguracije. Ova rešenja mogu se primeniti na različite probleme, sa više ili manje uspeha, u zavisnosti od toga koliko se dobro realna geometrija i stanja opterećenja slažu sa onim primenjenim u matematičkom modelu.

\section{Formulacija problema kontakta}

Kada dve inženjerske strukture fizički naležu jedna na drugu, a nisu kruto spojene i kada jedna drugoj predaju spoljne sile kroz zajedničku površinu dodira, za njih se kaže da su u kontaktu.

Slika 1 šematski prikazuje razmatrani kontakt-problem. Na njoj su prikazana dva tela $A$ i $B$, koja mogu biti označena i kao kontaktor i meta. U rešenju konačnog elementa telo $A$ sadrži čvorne granice konačnog elementa koji dolaze u kontakt sa segmentima ili čvorovima tela $B$. Mada su prikazana samo dva tela u kontaktu, mogu se analizirati kontaktni uslovi između većeg broja tela.

Osnovni uslovi kontakta duž površina kontakta su takvi da ne može da se dogodi materijalno preklapanje, a kao rezultat kontaktne sile su stvorene da deluju duž zone kontakta na telo $A$ i $B$. Ove sile su jednake i suprotne. Normalne sile mogu samo da vrše pritisak, a tangencijalne sile zadovoljavaju zakon otpornosti na trenje.

\section{Stanja kontakta u trodimenzio- nalnim problemima}

Stanje kontakta može se klasifikovati u četiri slučaja.

1. Otvoreno stanje - razmak između tela $A$ i $B$ ostaje otvoren, odnosno ne dolazi do kontakta:

$$
\Delta R_{a i}=\Delta R_{b i}=0,
$$

$$
\Delta q_{a i}-\Delta q_{b i} \equiv \Delta l_{i}(i=x, y, z)
$$

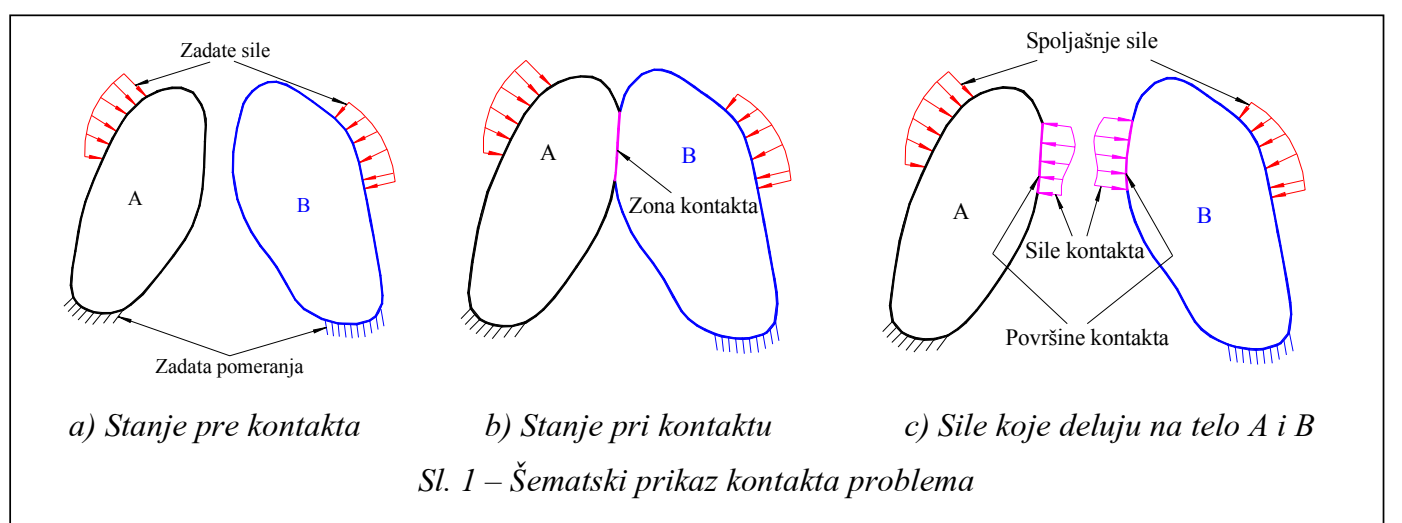


2. Kontakt prianjanja - razmak između tela $A$ i $B$ je zatvoren i ne dolazi do klizanja:

$$
\begin{aligned}
& \Delta R_{a i}=-\Delta R_{b i} \equiv \Delta R_{i}, \\
& \Delta q_{a i}-\Delta q_{b i}+\delta_{i}=0(i=x, y, z)
\end{aligned}
$$

3. Kontakt sa klizanjem - razmak između tela $A$ i $B$ ostaje zatvoren i klizanje se odvija u oba pravca $(x i y)$ :

$$
\begin{aligned}
& \Delta R_{a x}=-\Delta R_{b x}= \pm \mu \Delta R_{z} \\
& \Delta R_{a y}=-\Delta R_{b y}= \pm \mu \Delta R_{z} \\
& \Delta R_{a z}=-\Delta R_{b z} \equiv \Delta R_{z} \\
& \Delta q_{a x}-\Delta q_{b x} \equiv \Delta l_{x} \\
& \Delta q_{a y}-\Delta q_{b y} \equiv \Delta l_{y} \\
& \Delta q_{a z}-\Delta q_{b z}+\delta_{z}=0
\end{aligned}
$$

4. Mešovito stanje - razmak između tela $A$ i $B$ ostaje zatvoren i dolazi do klizanja u jednom pravcu ( $x$ ili $y$ ), ali ne do klizanja u drugom pravcu:

$$
\left.\begin{array}{l}
\Delta R_{a x}=-\Delta R_{b x}= \pm \mu \Delta R_{z} \\
\Delta R_{a y}=-\Delta R_{b y} \equiv \Delta R_{y} \\
\Delta R_{a z}=-\Delta R_{b z} \equiv \Delta R_{z} \\
\Delta q_{a x}-\Delta q_{b x} \equiv \Delta l_{x} \\
\Delta q_{a y}-\Delta q_{b y}+\delta_{y}=0 \\
\Delta q_{a z}-\Delta q_{b z}+\delta_{z}=0
\end{array}\right\}
$$

\begin{tabular}{|c|c|c|}
\hline \multicolumn{2}{|c|}{ Stanje } & \multirow{2}{*}{ Kriterijumi } \\
\hline pre & posle & \\
\hline \multirow{2}{*}{ Otvoreno } & otvoreno & $l_{z}>0$ \\
\hline & kontakt & $l_{z} \leq 0$ \\
\hline \multirow{4}{*}{ Prianjanje } & prianjanje & $\begin{array}{c}R_{z} \geq 0,\left|R_{x}\right| \leq \mu R_{z} \\
\left|R_{y}\right| \leq \mu R_{z}\end{array}$ \\
\hline & otvoreno & $R_{z}<0$ \\
\hline & klizanje & $\begin{array}{c}R_{z} \geq 0,\left|R_{x}\right| \geq \mu R_{z}, \\
\left|R_{y}\right|>\mu R_{z}\end{array}$ \\
\hline & mešovito & $\begin{array}{c}R_{z} \geq 0,\left|R_{x}\right| \geq \mu R_{z}, \\
\left|R_{y}\right|<\mu R_{z}\end{array}$ \\
\hline \multirow{4}{*}{ Klizanje } & prianjanje & $\begin{array}{c}R_{z} \geq 0, \Delta R_{x} \Delta l_{x}>0, \\
\Delta R_{y} \Delta l_{y}>0\end{array}$ \\
\hline & otvoreno & $R_{z}<0$ \\
\hline & klizanje & $\begin{array}{c}R_{z} \geq 0, \Delta R_{x} \Delta l_{x} \leq 0, \\
\Delta R_{y} \Delta l_{y} \leq 0\end{array}$ \\
\hline & mešovito & $\begin{array}{c}R_{z} \geq 0, \Delta R_{x} \Delta l_{x} \leq 0, \\
\Delta R_{y} \Delta l_{y}>0\end{array}$ \\
\hline \multirow{4}{*}{ Mešovito } & prianjanje & $\begin{array}{c}R_{z} \geq 0, \Delta R_{x} \Delta l_{x}>0 \\
\left|R_{y}\right| \leq \mu R_{z}\end{array}$ \\
\hline & otvoreno & $R_{z}<0$ \\
\hline & klizanje & $\begin{array}{c}R_{z} \geq 0, \Delta R_{x} \Delta l_{x} \leq 0, \\
\left|R_{y}\right|>\mu R_{z}\end{array}$ \\
\hline & mešovito & $\begin{array}{c}R_{z} \geq 0, \Delta R_{x} \Delta l_{x} \leq 0 \\
\left|R_{y}\right| \leq \mu R_{z}\end{array}$ \\
\hline
\end{tabular}

Pretpostaviće se da je $q_{j i}$ čvorno pomeranje, a $R_{j i}$ sila u čvoru na površini kontakta, gde indeks $j$ označava telo, a $i$ koordinatu.

\section{Odredivanje stanja kontakta pomoću elemenata kontakta}

Ukoliko se mogu objasniti uslovi kontakta pomoću elemenata kontakta, može se doći do znatnog kompjuterskog pojednostavljenja. $U$ tabeli 1 dati su elementi kontakta koji povezuju čvorni par kontakta sa sledećim konstitutivnim odnosom. 
Uopštena matrična jednačina stanja kontakta predstavljena je u sledećem obliku:

$\left(\begin{array}{ccccccccc}0 & 0 & 0 & 0 & 0 & 0 & e_{x}^{1} & 0 & -e_{z x} \\ 0 & 0 & 0 & 0 & 0 & 0 & 0 & e_{y}^{1} & -e_{z y} \\ 0 & 0 & 0 & 0 & 0 & 0 & 0 & 0 & e_{z}^{1} \\ 0 & 0 & 0 & 0 & 0 & 0 & e_{x}^{2} & 0 & e_{z x} \\ 0 & 0 & 0 & 0 & 0 & 0 & 0 & e_{y}^{2} & e_{z y} \\ 0 & 0 & 0 & 0 & 0 & 0 & 0 & 0 & e_{z}^{2} \\ e_{x}^{5} & 0 & 0 & e_{x}^{4} & 0 & 0 & e_{x}^{3} & 0 & 0 \\ 0 & e_{y}^{5} & 0 & 0 & e_{y}^{4} & 0 & 0 & e_{y}^{3} & 0 \\ 0 & 0 & e_{z}^{5} & 0 & 0 & e_{z}^{4} & 0 & 0 & e_{z}^{3}\end{array}\right)\left\{\begin{array}{c}\Delta q_{a x} \\ \Delta q_{a y} \\ \Delta q_{a z} \\ \Delta q_{b x} \\ \Delta q_{b y} \\ \Delta q_{b z} \\ \Delta R_{x}^{*} \\ \Delta R_{y}^{*} \\ \Delta R_{z}^{*}\end{array}\right\}=\left\{\begin{array}{c}\Delta R_{a x}^{*} \\ \Delta R_{a y}^{*} \\ \Delta R_{a z}^{*} \\ \Delta R_{b x}^{*} \\ \Delta R_{b y}^{*} \\ \Delta R_{b z}^{*} \\ \delta_{x}^{*} \\ \delta_{y}^{*} \\ \delta_{z}^{*}\end{array}\right\}$

gde svaki elemenat $e_{i}^{n}, e_{z x}, e_{z y}, \delta_{i}^{*}$ itd. u jednačini (5) ima vrednost koja zavisi od stanja kontakta.

\section{Jednačine inkrementalne ravnoteže}

Najčešći problemi kontakta izrazito su nelinearni i zavise od putanje opterećenja. Nelinearnosti proizilaze iz promenjivosti površine kontakta sa promenom opterećenja i efekta trenja. Kako se opterećenje povećava, kontaktni čvorni parovi dolaziće u kontakt. Imajući to u vidu, kao i nepovratni karakter fenomena trenja, formulisaće se inkrement opterećenja kako bi se rešili nelinearni problemi kontakta. Ovom prilikom intenzitet opterećenja koji prouzrokuje promenu stanja kontakta jednog para čvora kontakta uzet je kao inkrement opterećenja, što je analogno inkrementalno-iterativnoj proceduri za probleme elastičnosti i plastičnosti.
Radi nalaženja rešenja opštih jednačina kontaktnog problema pomoću metode konačnog elementa koristiće se princip inkrementalnog virtualnog rada, koji kaže da je zbir radova svih spoljašnjih i svih unutrašnjih sila pri bilo kom virtualnom pomeranju tačaka tela $\delta u_{i}$, na koje ovaj sistem sila deluje, jednak nuli, i za telo $A$ može se izraziti sledećom jednačinom:

$$
\begin{aligned}
& \iiint_{V} \Delta \sigma_{i j} \delta \Delta \varepsilon_{i j} d V-\iiint_{V} \Delta p_{i} \delta \Delta u_{i} d V- \\
& -\iint_{S} \Delta T_{i} \delta \Delta u_{i} d s-\iint_{c} \Delta R_{i} \delta \Delta u_{i} d s=0
\end{aligned}
$$

gde je:

$\Delta p_{i}$ - zapreminska sila;

$\Delta T_{i}$ - površinska sila;

$\Delta R_{i}$ - sila kontakta;

$c$ - površina kontakta;

$S$ - granična površina tela izuzev površine $c$.

Transformacijom jednačine (6) dobija se jednačina krutosti:

$$
\left(K_{a}\right)\left\{\Delta q_{a}\right\}=\left\{\Delta F_{a}\right\}+\left\{\Delta F_{c}\right\}
$$

gde je:

$K_{a}$ - matrica krutosti,

$\Delta q_{a}-$ vektor čvornih pomeranja.

U jednačini (7) $\left\{\Delta F_{a}\right\}$ predstavlja ekvivalentni vektor čvorne sile tela, dobijen iz drugog i trećeg izraza jednačine (6).

Vektor kontaktne sile $\left\{\Delta F_{c}\right\}$ predstavljen je izrazom:

$$
\left\{\Delta F_{c}\right\}=\iint_{c} \Delta R_{i} \delta \Delta u_{i} d s
$$


Pošto je sila kontakta $R_{i}$ nepoznata ona se ne može kao takva integraliti. Zbog toga ce ekvivalentna čvorna sila $\left\{\Delta F_{c}\right\}$ biti razmatrana kao nepoznati varijabilni vektor.

Na sličan način kao za telo $A$ bira se sledeća jednačina za telo $B$ :

$\left(K_{b}\right)\left\{\Delta q_{b}\right\}=\left\{\Delta F_{b}\right\}+\left\{\Delta F_{c}\right\}$

gde je:

$K_{b}$ - matrica krutosti;

$\Delta q_{b}$ - vektor čvornih pomeranja tela $\mathrm{B}$.

Ovde je $\left\{\Delta F_{b}\right\}$ ekvivalentni vektor čvorne sile tela i $\left\{\Delta F_{c}\right\}$ vektora kontaktne sile.

Treba napomenuti da se jednačine (7) i (9) nalaze u međusobnom odnosu preko vektora kontaktne sile $\left\{\Delta F_{c}\right\}$. Uzimajući da je $\left\{\Delta F_{c}\right\}$ rezultanta vektora $\Delta R_{a i}$ ili $\Delta R_{b i}$ u jednačini (5) i deo $\left\{\Delta q_{j}\right\}$ duž površine kontakta shodno $\Delta q_{j i}$, dobija se:

$$
\begin{aligned}
& \left\{\Delta F_{c}\right\}=\sum_{c}\left(\begin{array}{ccc}
e_{x}^{1} & 0 & -e_{z x} \\
0 & e_{y}^{1} & -e_{z y} \\
0 & 0 & e_{z}^{1}
\end{array}\right)\left\{\begin{array}{l}
\Delta R_{x}^{*} \\
\Delta R_{y}^{*} \\
\Delta R_{z}^{*}
\end{array}\right\}= \\
& =-\sum_{c}\left(\begin{array}{ccc}
e_{x}^{2} & 0 & e_{z x} \\
0 & e_{y}^{2} & e_{z y} \\
0 & 0 & e_{z}^{2}
\end{array}\right)\left\{\begin{array}{l}
\Delta R_{x}^{*} \\
\Delta R_{y}^{*} \\
\Delta R_{z}^{*}
\end{array}\right\}
\end{aligned}
$$

i

$$
\left\{\Delta q_{i}\right\}=\left\{\Delta q_{j i}\right\} \text { na } c
$$

Ovde su rezimei izvedeni za sve čvorne tačke duž površine kontakta $c$. Za svaki od čvorova u paru definiše se vektor inkrementa sile kontakta kao:

$$
\left\{\Delta R^{*}\right\}=\sum_{c}\left\{\begin{array}{l}
\Delta R_{x}^{*} \\
\Delta R_{y}^{*} \\
\Delta R_{z}^{*}
\end{array}\right\}
$$

i vektor relativnog pomeranja između parova kontaktnih čvorova pomoću:

$\left\{\delta_{c}\right\}=\sum_{c}\left\{\begin{array}{l}\delta_{x}^{*} \\ \delta_{y}^{*} \\ \delta_{z}^{*}\end{array}\right\}$

Sintezom jednačine (7) i (8), koristeći jednačine (5), (10) i (11), dobija se:

$\left(\begin{array}{ccc}K_{a} & 0 & K_{a c} \\ 0 & K_{b} & K_{b c} \\ K_{c a} & K_{c b} & K_{c c}\end{array}\right)\left\{\begin{array}{l}\Delta q_{a} \\ \Delta q_{b} \\ \Delta R^{*}\end{array}\right\}=\left\{\begin{array}{c}\Delta F_{a} \\ \Delta F_{b} \\ \delta_{c}\end{array}\right\}$

Ovde $K_{a c}, K_{b c} K_{c c,} K_{c b}$ i $K_{c a}$ odgovaraju matricama koeficijenta u jednačini (5) i dati su pomoću:

$$
\begin{aligned}
& K_{a c}=\sum_{c}\left(\begin{array}{ccc}
e_{x}^{1} & 0 & -e_{z x} \\
0 & e_{y}^{1} & -e_{z y} \\
0 & 0 & e_{z}^{1}
\end{array}\right) \\
& K_{b c}=\sum_{c}\left(\begin{array}{ccc}
e_{x}^{2} & 0 & e_{z x} \\
0 & e_{y}^{2} & e_{z y} \\
0 & 0 & e_{z}^{2}
\end{array}\right)
\end{aligned}
$$




$$
\begin{aligned}
& K_{c c}=\sum_{c}\left(\begin{array}{ccc}
e_{x}^{3} & 0 & 0 \\
0 & e_{y}^{3} & 0 \\
0 & 0 & e_{z}^{3}
\end{array}\right) \\
& K_{c b}=\sum_{c}\left(\begin{array}{ccc}
e_{x}^{4} & 0 & 0 \\
0 & e_{y}^{4} & 0 \\
0 & 0 & e_{z}^{4}
\end{array}\right) \\
& K_{c a}=\sum_{c}\left(\begin{array}{ccc}
e_{x}^{5} & 0 & 0 \\
0 & e_{y}^{5} & 0 \\
0 & 0 & e_{z}^{5}
\end{array}\right)
\end{aligned}
$$

Ako se $\left\{\Delta R^{*}\right\}$ razmatra kao nepoznata promenljiva vektora, kao u jednačini (14), nije potrebno promeniti veličinu jednačine u procesu iteracije. I kao deo rešenja dobija se $\left\{\Delta R^{*}\right\}$, odnosno ekvivalentne čvorne sile u odnosu sa silama kontakta ili relativna pomeranja između čvornih parova kontakta koji su neophodni za diskriminaciju stanja kontakta. Algoritam kompjuterske procedure postaje jednostavniji.

Pored toga, samo $K_{a c,} K_{b c,} K_{c c}, K_{c b} \mathrm{i}$ $K_{c a}$ iz jednačine (14) varira u procesu iteracije, pa pošto se samo jednom izvodi Gausova procedura eliminacije za pun sistem jednačine (15) u prvoj iteraciji, dovoljno je rastaviti samo jednačine koje se odnose na čvorne parove kontakta.

Rešenje se može poboljšati bez rešavanja velikog broja simultanih jednačina na svakom stupnju, tako da proces iteracije može da se izvede znatno ekonomičnije.

\section{Odredivanje inkrementa opterećenja}

Pretpostavlja se da je na kraju prethodnog koraka $n C^{(n)}$ stanje kontakta. Takođe, pretpostavlja se da je $\left\{q^{(n)}\right\}$ vektor čvornog pomeranja i $\left\{R^{(n)^{*}}\right\}$ vektor sile kontakta. Rešavanjem vektora čvornog pomeranja $\left\{\Delta q^{(n)}\right\}$ i vektora sile kontakta $\left\{\Delta R^{(n)^{*}}\right\}$ pod uslovom kontakta $C^{(n)}$ i fiksnog opterećenja $\{\Delta F\}$, a primenom $\left\{\Delta q^{(n)}\right\}$ i $\left\{\Delta R^{(n)^{*}}\right\}$ kao i $\left\{q^{(n)}\right\}$ i $\left\{R^{(n)^{*}}\right\}$, može se proračunati koeficijent opterećenja $\alpha^{(n)}$ koji je definisan izrazom:

$\alpha^{(n)}=\frac{\left\{\Delta F^{(n)^{*}}\right\}}{\Delta F}$

gde je $\left\{\Delta F^{(n)^{*}}\right\}$ inkrement opterećenja $n$ -tog koraka.

Iz $\alpha^{(n)}$ dobija se opterećenje $\left\{F^{(n+1)}\right\}$, pomeranje $\left\{q^{(n+1)}\right\}$ i sila kontakta $\left\{R^{(n+1)^{*}}\right\}$ kod novog koraka $(n+1)$ :

$$
\left.\begin{array}{c}
\left\{F^{(n+1)}\right\}=\left\{F^{(n)}\right\}+\alpha^{(n)}\{\Delta F\} \\
\left\{q^{(n+1)}\right\}=\left\{q^{(n)}\right\}+\alpha^{(n)}\left\{\Delta q^{(n)}\right\} \\
\left.R^{(n+1)^{*}}\right\}=\left\{R^{(n)^{*}}\right\}+\alpha^{(n)}\left\{\Delta R^{(n)^{*}}\right\}
\end{array}\right\}
$$

Vrednost $\alpha^{(n)}$ je manja od $\alpha^{(n)^{*}}$ proračunato pomoću sledećih jednačina za sve čvorne parove kontakta.

1. Od otvorenog stanja do stanja kontakta: 
$l_{z}^{(n+1)}=l_{z}^{(n)}+\alpha^{(n)^{*}}\left(\Delta q_{a z}^{(n)}-\Delta q_{b z}^{(n)}\right)=$

$=l_{z}^{(n)}+\alpha^{(n)^{*}} \Delta l_{z}^{(n)}=0$

Shodno tome, $\alpha^{(n)^{*}}$ za ovaj slučaj je dat putem:

$\alpha^{(n)^{*}}=-\frac{l_{z}^{n}}{\Delta l_{z}^{n}}$

2. Od stanja kontakta do otvorenog stanja:

$$
R_{z}^{(n+1)}=R_{z}^{(n)}+\alpha^{(n) *}\left(\Delta R_{z}^{(n)}\right)=0
$$

Ovde je:

$$
\alpha^{(n)^{*}}=-\frac{R_{z}^{n}}{\Delta R_{z}^{n}}
$$

3. Od čvrstog stanja do stanja klizanja $\alpha^{(n)^{*}}$ za klizanje u pravcu $x$ dato je kao:

$\left|R_{x}^{(n+1)}\right|-\mu R_{z}^{(n+1)}=\left|R_{x}^{(n)}+\alpha^{(n)^{*}} \Delta R_{x}^{(n)}\right|-$

$-\mu\left(R_{z}^{(n)}+\alpha^{(n)^{*}} \Delta R_{z}^{(n)}\right)=0$

Sada $\alpha^{(n)^{*}}$ postaje:

$$
\begin{aligned}
& \Delta R_{z}^{(n)} \cdot R_{x}^{(n)} \leq \Delta R_{x}^{(n)} \cdot R_{z}^{(n)} \\
& \alpha^{(n)^{*}}=-\frac{R_{x}^{(n)}-\mu R_{z}^{(n)}}{\Delta R_{x}^{(n)}-\mu \Delta R_{z}^{(n)}} \\
& \Delta R_{z}^{(n)} \cdot R_{x}^{(n)}>\Delta R_{x}^{(n)} \cdot R_{z}^{(n)} \\
& \alpha^{(n)^{*}}=-\frac{R_{x}^{(n)}+\mu R_{z}^{(n)}}{\Delta R_{x}^{(n)}+\mu \Delta R_{z}^{(n)}}
\end{aligned}
$$

Sufiks $y$ trebalo bi postaviti na mesto sufiksa $x$ za stanje klizanja $\mathrm{u} y$ pravcu.

\section{Stanja kontakta}

Neka $\left\{F^{(n-1)}\right\}$ i $\left\{C^{(n-1)}\right\}$ budu opterećenja i stanje kontakta na $n$-tom koraku. Pretpostaviće se da se povećava opterećenje $\left\{F^{(n-1)}\right\}$ pomoću inkrementa opterećenja $\alpha^{(n-1)}\{\Delta F\}$ prema prethodno navedenoj metodi i da se stanje kontakta $\left\{C^{(n-1)}\right\}$ menja u novo $\left\{C^{(n)}\right\}$, kao što je prikazano na slici 2. Za vreme opterećenja stanje kontakta $\left\{C^{(n-1)}\right\}$ ostaje konstantno zbog definicije inkrementa.

Novo stanje kontakta $\left\{C^{(n)}\right\}$ nije jedinstveno. Radi nastavka procedure neophodno je raspolagati potrebnim informacijama kao relevantnim pokazateljima. Na primer, ako kontakt čvornog para pod otvorenim stanjem dođe u kontakt, mora da se odredi da li je došlo do klizanja ili ne. Kao drugi primer, mora se otkriti da li čvorni par kontakta u stanju

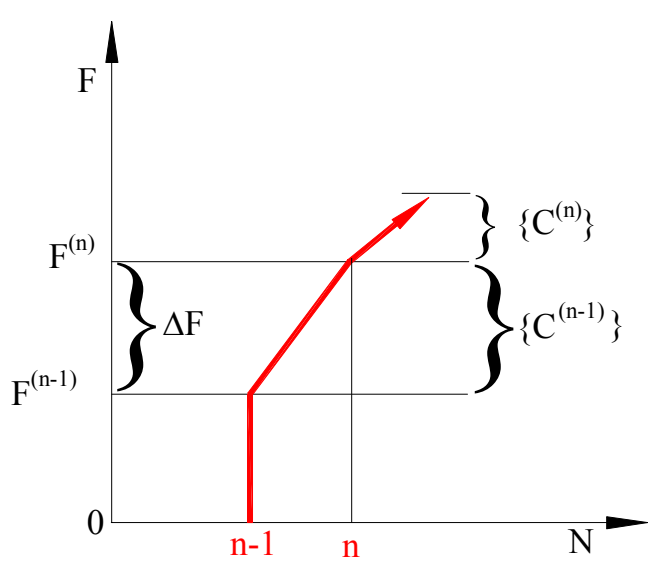

Sl. 2 - Promene u stanju kontakta za inkrementalno opterećenje 


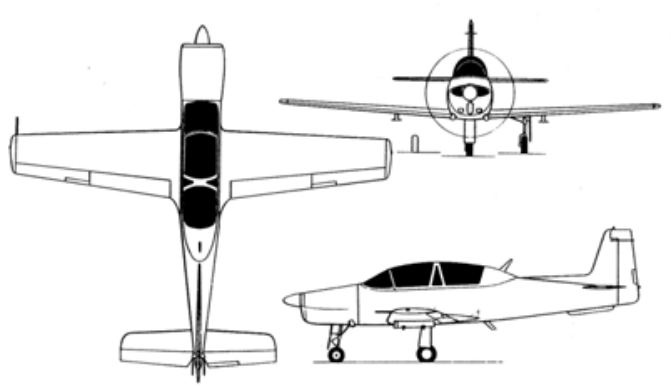

Sl. 3 - Avion Lasta

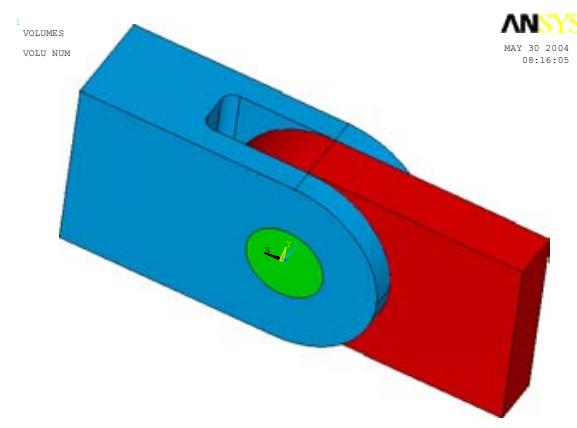

Sl. 4-Model 3D

klizanja dolazi do prianjanja. Zbog toga treba da se dobije rešenje $\Delta R^{(n)}, \Delta l_{x}$, itd. pod uslovom $\left\{C^{(n)}\right\}$ i fiksnog vektora opterećenja $\{\Delta F\}, \mathrm{i}$ da se kontroliše da li su uslovi prikazani u tabeli 1 zadovoljavajući za sve čvorne parove kontakta. Svaka iteracija mora da se izvede dok se ne postigne konvergencija.

\section{Analiza okova}

Primer proračuna biće pokazan na avionu Lasta - jednomotornom dvosedu niskokrilcu. U osnovnoj nameni to je školski klipni avion namenjen za osnovnu obuku i trenažu pilota u letenju sa i bez spoljne vidljivosti i za obuku $u$ instrumentalnom letu.
Krilo aviona, koje je trapeznog oblika, preko svojih okova vezano je za odgovarajuće okove na okvirima trupa. Ovi okovi namenjeni su za međusobno spajanje krila sa trupom. Izrađeni su od duraluminijuma i spojeni vijkom. Analiza je izvršena na trodimenzionalnom modelu (slika 4) primenom programskog paketa ANSYS. Mreža trodimenzionalnog modela (slika 5) urađena je pomoću konačnog elementa oblika tetraedra, sa čvorovima u temenima i na sredinama stranica (slika 6).

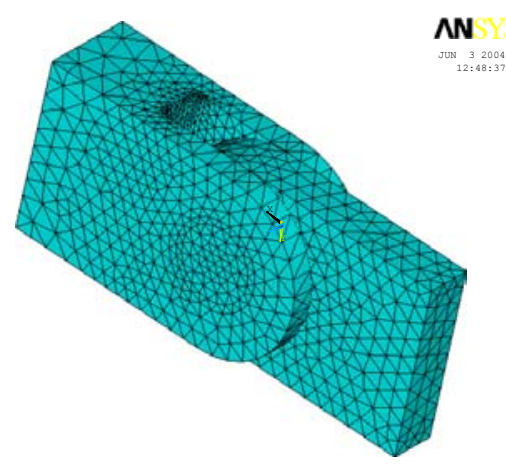

Sl. 5 - Umrežen model

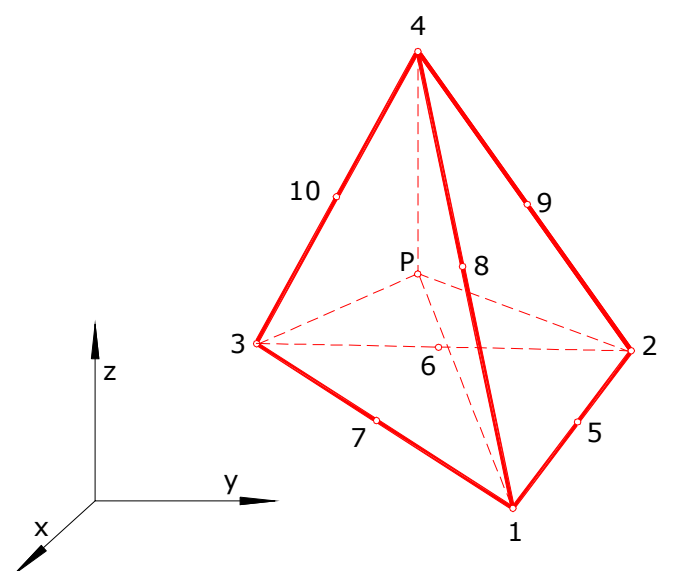

Sl. 6-Konačni element oblika tetraedra 


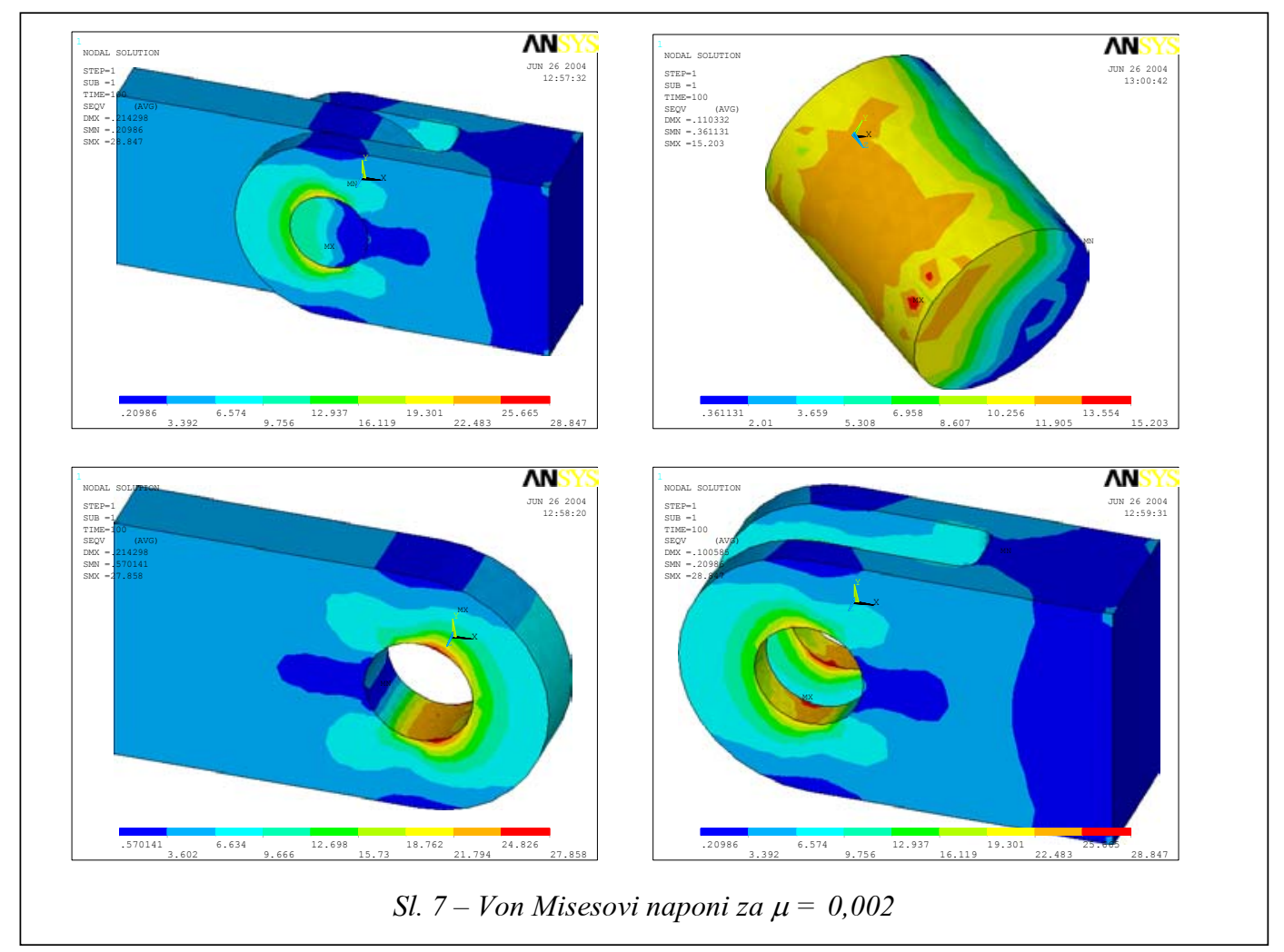

Analiza okova izvršena je sa vrednostima koeficijenata trenja u dijapazonu od 0,002 do 0,3 . Na slici 7 dat je grafički prikaz rezultata analize problema kontakta veze krilo-trup lakog školskog aviona Lasta, sa koeficijentom trenja $\mu=0,002$.

\section{Uticaj trenja na raspodelu napona}

Na slikama 9 i 10 prikazani su rezultati analize problema kontakta veze krilo-trup lakog školskog aviona. Primarna pažnja pri toj analizi bila je usmerena na uključivanje uticaja trenja između osovinice i uški, odnosno na preraspodelu naponskih stanja u uškama. Radi toga je vršena analiza uticaja koeficijenta trenja $\mu$ na raspodelu naponskog stanja $u$ predmetnoj vezi krilo-trup, odnosno u samim uškama. Analiza je vršena za vrednosti koeficijenta trenja $u$ dijapazonu 0,002 do 0,3 . Za ovu vrstu problema koeficijent trenja 0,3 je previsok, ali zbog sistematičnosti je uključen u analizu. Rezultati numeričke analize upoređeni su sa eksperimentalnim rezultatima gde je dobijena dobra saglasnost.

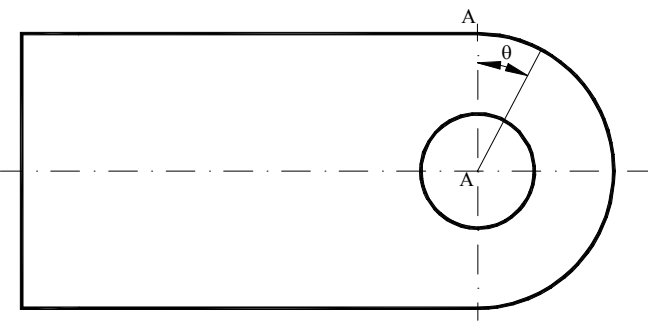

Sl. 8 - Šema uške 


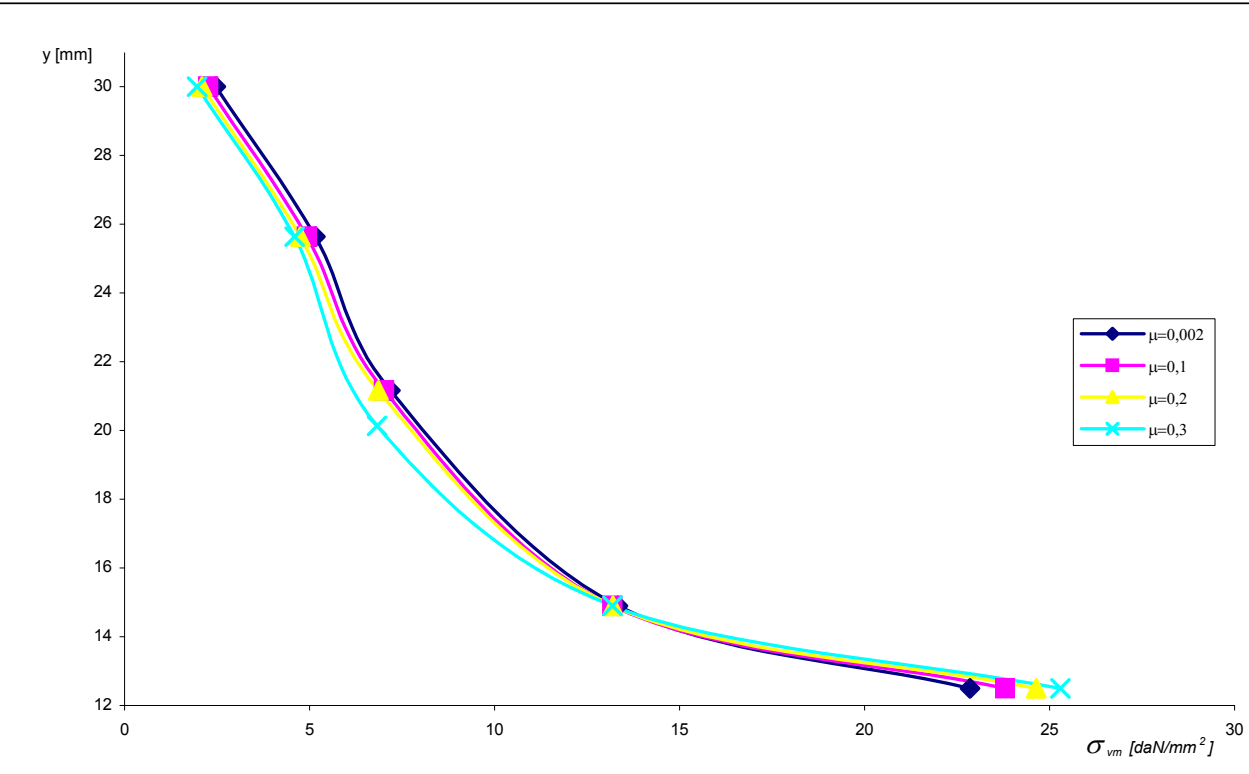

Sl. 9 - Raspodela von Misesovih napona - za presek A-A spoljašnje uške

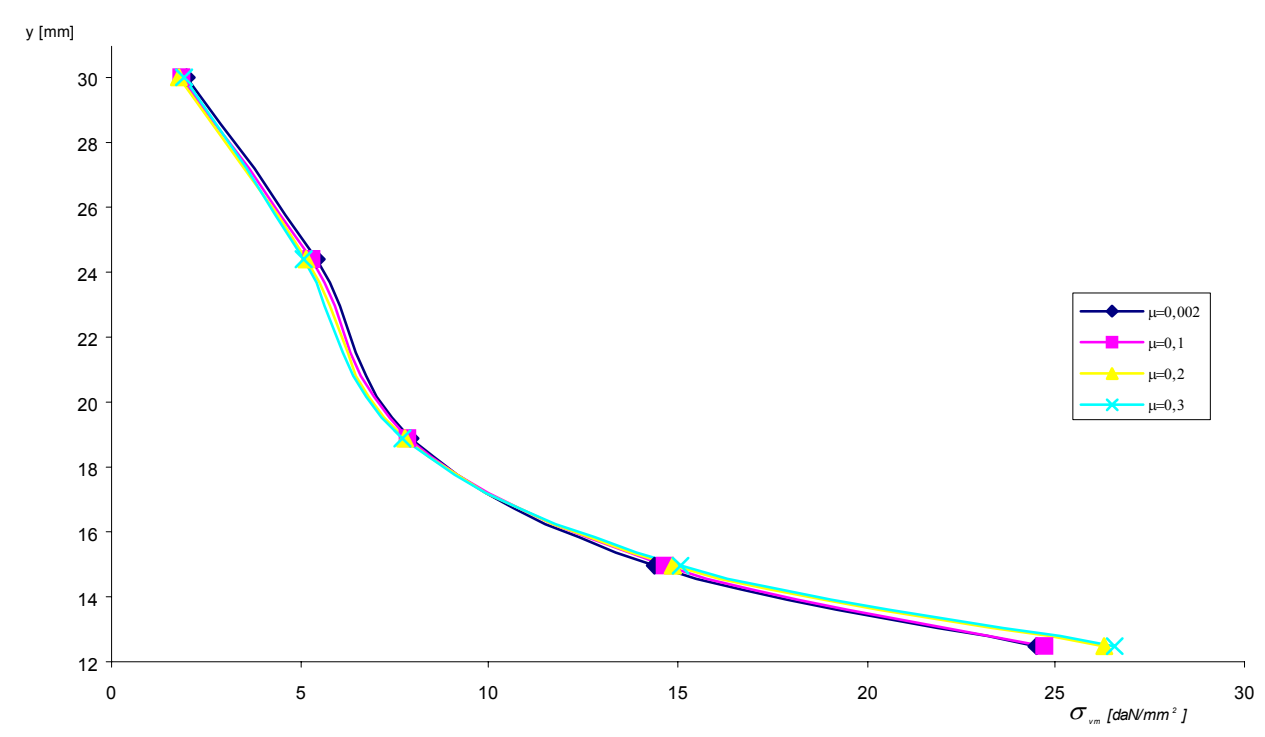

Sl. 10 - Raspodela von Misesovih napona -- za presek A-A unutrašnje uške

Međutim, u razmatranom problemu kontakta čelik-duraluminijum veze krilo-trup, uočeno je sledeće:
- uvođenje koeficijenta trenja utiče na promenu naponskog stanja, kako u unutrašnjoj, tako i u spoljnjoj ušci (slike 9 i 10). 
Uočava se da je povećanje maksimalnog napona $\mathrm{u}$ uškama za koeficijente trenja $\mathrm{u}$ području $\mu=0,002$ do $\mu=0,2$ za oko $5 \%$. To potvrđuje da ga je potrebno uzeti u obzir pri analizi problema kontakta;

- prema očekivanju, za koeficijente trenja $u$ području $\mu=0,002$ do $\mu=0,2$ nije došlo do bitnije promene položaja maksimalnog napona $\theta$, kao što je ilustrovano u tabeli 2.

Položaj maksimalnog napona $\theta$

Tabela 2

\begin{tabular}{|c|c|c|}
\hline$\mu$ & $\begin{array}{c}\theta \\
\text { spoljašnje uške }\end{array}$ & $\begin{array}{c}\theta \\
\text { unutrašnje uške }\end{array}$ \\
\hline 0,002 & 18,6688 & 17,7723 \\
\hline 0,1 & 18,6791 & 17,8049 \\
\hline 0,2 & 18,6824 & 17,8309 \\
\hline 0,3 & 18,6863 & 17,8575 \\
\hline
\end{tabular}

\section{Zaključak}

Pokazano je da su problemi kontakta izrazito specifični i zahtevaju vrlo složene analize za njihovo rešavanje. Pošto je poznato da je ova klasa problema izuzetno nelinearna, uz pretpostavke da je problem kontakta analiziran za linearno elastična tela i male deformacije, nelinearnost problema svela se na površinsku nelinearnost.
$\mathrm{Na}$ osnovu rezultata dobijenih analizom okova na avionu Lasta, može se zaključiti da se analizom problema kontakta sa uticajem trenja dolazi do realnije slike naponskog stanja, koja je bitna za procenu veka strukturalnih elemenata pri analizi čvrstoće na zamor. Pošto i trenje utiče na povećanje napona u konstrukciji, treba ga uključiti u analizu.

I pored svega navedenog, polje za analizu problema kontakta je veoma veliko, i postoji još mnogo aspekata koje treba obuhvatiti analizom.

Literatura:

[1] Josifović, M.: Osnovi strukturalne analize aerotehničkih konstrukcija, Mašinski fakultet, Beograd, 1979.

[2] Sekulović, M.: Metod konačnih elemenata, Građevinska knjiga, Beograd, 1984.

[3] Tsuta, T.; Yamaji, S.: Finite element analysis of contact problem, Theory and Practice in Finite Element Structural Analysis, University of Tokyo Press, 1973, pp.177-194.

[4] Okamoto, N.; Nakazawa, M.: Finite element incremental contact analysis with various frictional conditions. Int. J. Numer. Meth. Engng. 14, 337-357 (1979).

[5] Chen, Wen-Hwa; Yeh, Jyi-Tyan: Finite element analysis of finite deformationcontact problems with friction, Comput. Struct. 29, 423-436 (1988)

[6] Gaertner, R.: Investigation of plane elastic contact allowing for friction. Comput.Struct. 7, 59-63 (1977).

[7] Chan, S. K.; Tuba I. S.: A finite element method for contact problems of solidbodies-part I. Theory and validation. Int. J. Mech. Sci. 13, 615-625 (1971).

[8] Ohte, B.: Analysis of elastic contact stress by using finite element method, Trans. Jap. Soc. Mech. Engng, 38, 2210 2216 (1972) (in Japanese).

[9] Sachdeva T. D.; Ramakrishnan, C. V.: A finite element solution for the two-dimensional elastic contact problems with friction. Int. J. Numer. Meth. Engng. 17, 1257-1271 (1981). 


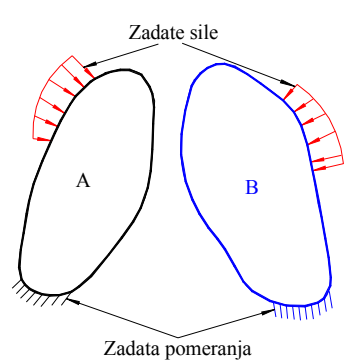

a) Stanje pre kontakta

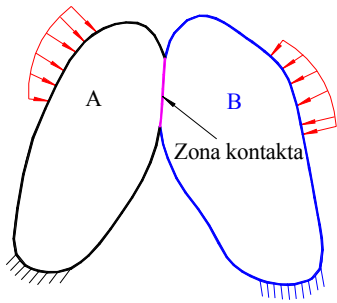

b) Stanje pri kontaktu

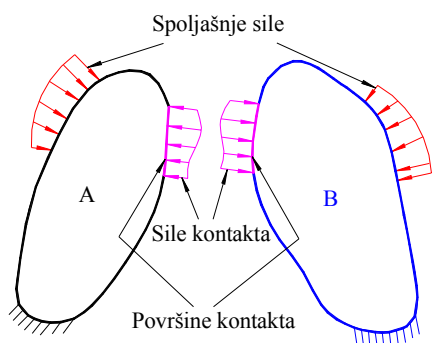

c) Sile koje deluju na telo $A$ i B

Sl. 1 - Šematski prikaz kontakta problema

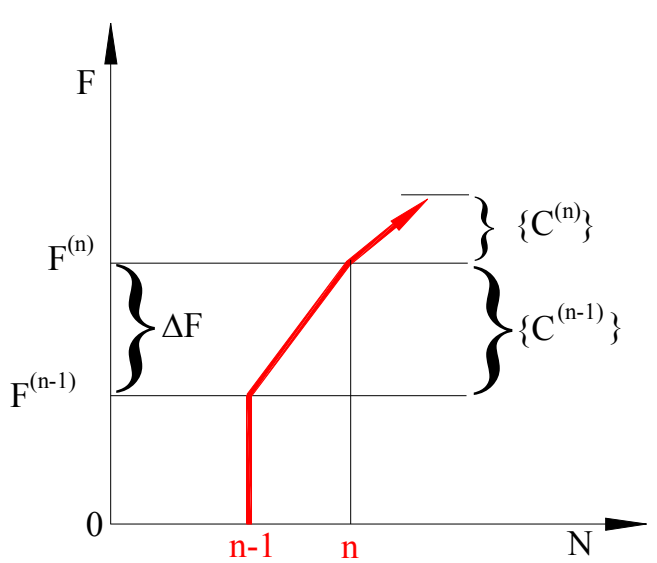

Sl. 2 - Promene u stanju kontakta za inkrementalno opterećenje 


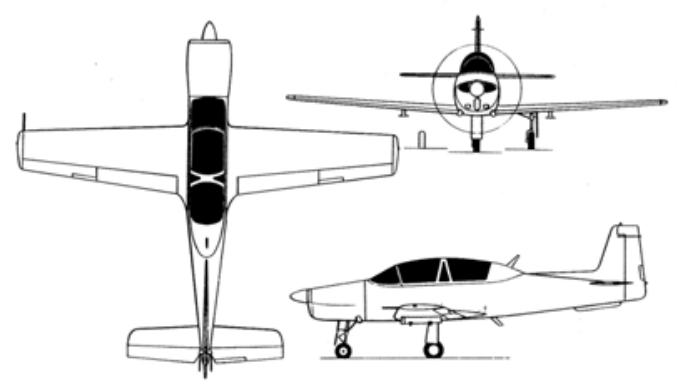

Sl. 3 - Avion Lasta

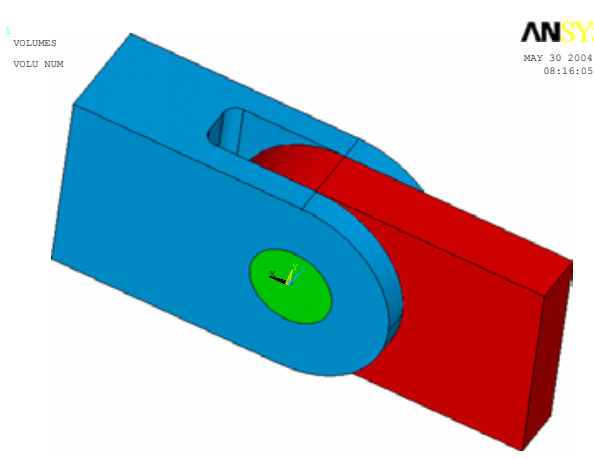

Sl. 4-Model 3D

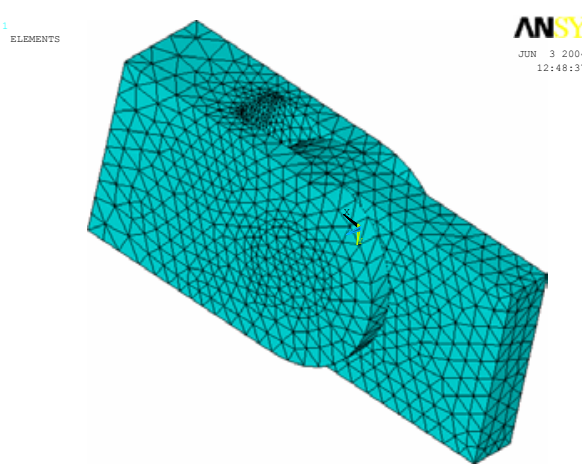

Sl. 5 - Umrežen model 


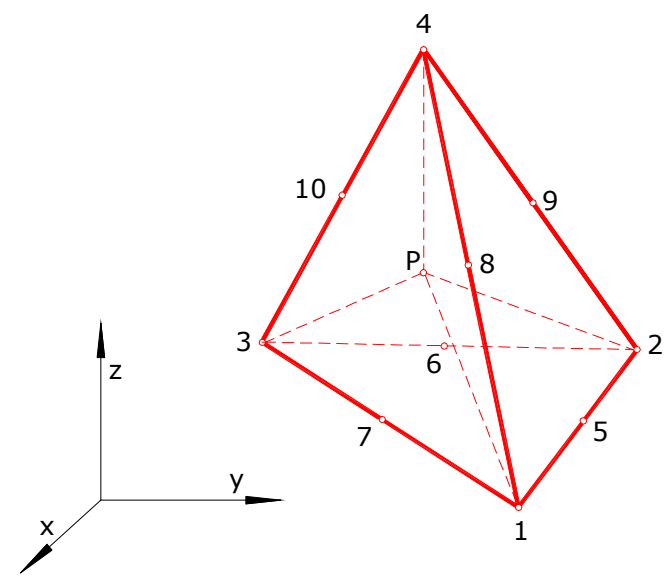

Sl. 6 - Konačni element oblika tetraedra
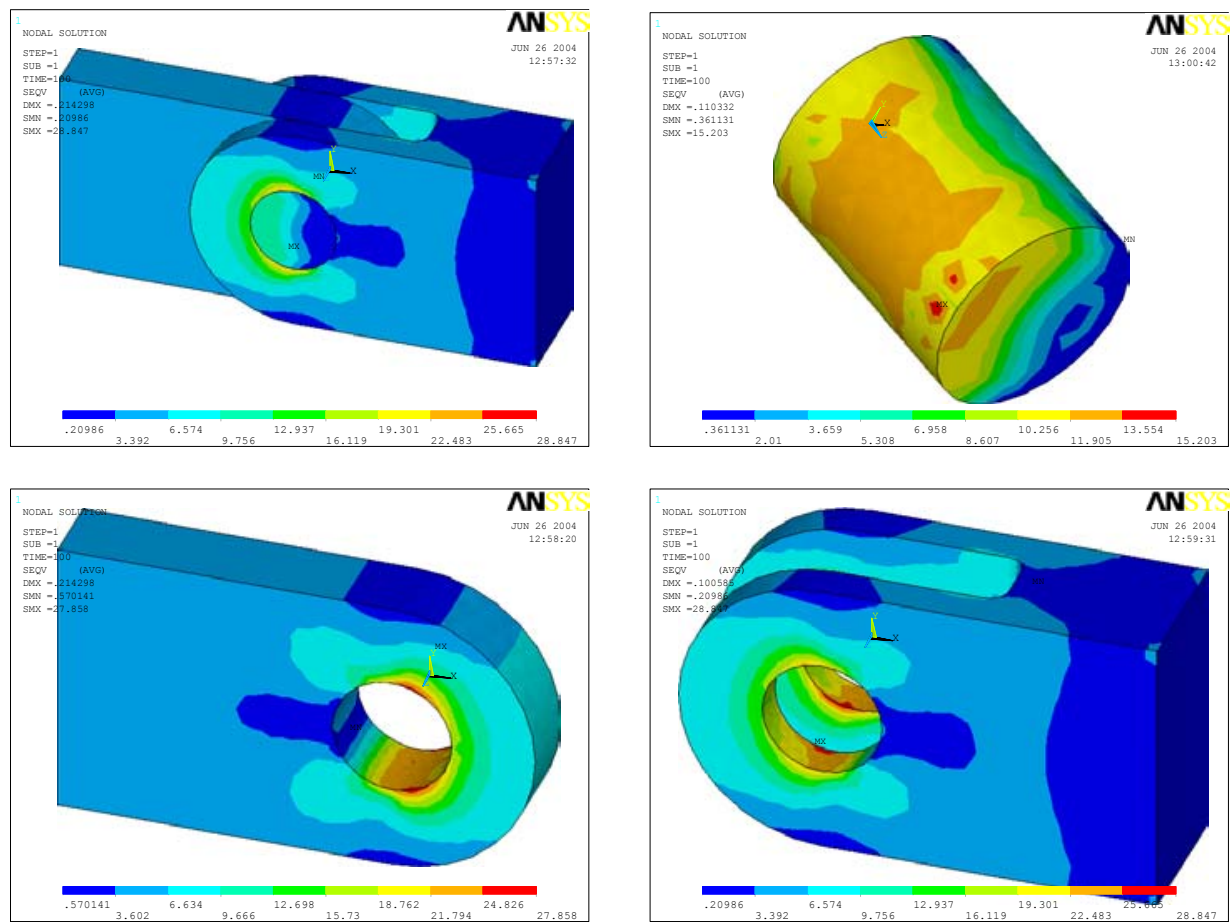

Sl. 7 - Von Mises-ovi naponi za $\mu=0,002$ 


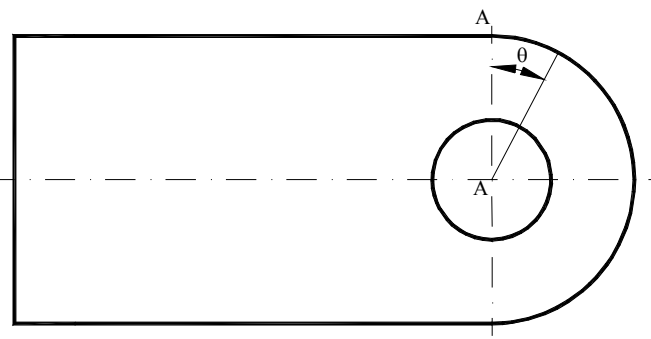

Sl. 8 - Šema uške 